\title{
BMJ Open Mobile phone use and incidence of brain tumour histological types, grading or anatomical location: a population- based ecological study
}

\author{
Ken Karipidis, ${ }^{1}$ Mark Elwood, ${ }^{2}$ Geza Benke, ${ }^{3}$ Masoumeh Sanagou, ${ }^{1}$ \\ Lydiawati Tjong, ${ }^{1}$ Rodney $\mathrm{J}$ Croft $^{4}$
}

To cite: Karipidis K, Elwood M, Benke G, et al. Mobile phone use and incidence of brain tumour histological types, grading or anatomical location: a population-based ecological study. BMJ Open 2018;8:e024489. doi:10.1136/ bmjopen-2018-024489

- Prepublication history and additional material for this paper are available online. To view these files, please visit the journal online (http://dx.doi. org/10.1136/bmjopen-2018024489).

Received 30 May 2018 Revised 6 August 2018 Accepted 5 November 2018

Check for updates

(C) Author(s) (or their employer(s)) 2018. Re-use permitted under CC BY-NC. No commercial re-use. See rights and permissions. Published by BMJ.

${ }^{1}$ Australian Radiation Protection and Nuclear Safety Agency, Yallambie, Victoria, Australia ${ }^{2}$ School of Population Health, University of Auckland, Auckland, New Zealand

${ }^{3}$ School of Public Health and Preventive Medicine, Monash University, Melbourne, Victoria, Australia

${ }^{4}$ Australian Centre for Electromagnetic Bioeffects Research, Illawarra Health and Medical Research Institute,

University of Wollongong,

Wollongong, New South Wales, Australia

Correspondence to

Dr Ken Karipidis;

ken.karipidis@arpansa.gov.au

\section{ABSTRACT}

Objective Some studies have reported increasing trends in certain brain tumours and a possible link with mobile phone use has been suggested. We examined the incidence time trends of brain tumour in Australia for three distinct time periods to ascertain the influence of improved diagnostic technologies and increase in mobile phone use on the incidence of brain tumours.

Design In a population-based ecological study, we examined trends of brain tumour over the periods 19821992, 1993-2002 and 2003-2013. We further compared the observed incidence during the period of substantial mobile phone use (2003-2013) with predicted (modelled) incidence for the same period by applying various relative risks, latency periods and mobile phone use scenarios.

Setting National Australian incidence registration data on primary cancers of the brain diagnosed between 1982 and 2013.

Population 16825 eligible brain cancer cases aged 2059 from all of Australia (10083 males and 6742 females).

Main outcome measures Annual percentage change (APC) in brain tumour incidence based on Poisson regression analysis.

Results The overall brain tumour rates remained stable during all three periods. There was an increase in glioblastoma during 1993-2002 (APC 2.3, 95\% Cl 0.8 to 3.7 ) which was likely due to advances in the use of MRI during that period. There were no increases in any brain tumour types, including glioma $(-0.6,-1.4$ to 0.2$)$ and glioblastoma $(0.8,-0.4$ to 2.0$)$, during the period of substantial mobile phone use from 2003 to 2013. During that period, there was also no increase in glioma of the temporal lobe $(0.5,-1.3$ to 2.3$)$, which is the location most exposed when using a mobile phone. Predicted incidence rates were higher than the observed rates for latency periods up to 15 years.

Conclusions In Australia, there has been no increase in any brain tumour histological type or glioma location that can be attributed to mobile phones.

\section{INTRODUCTION}

Since its introduction in the mid-80s mobile phone use has grown rapidly worldwide. When using a mobile phone against the
Strengths and limitations of this study

- This study investigated incidence time trends for different brain tumour histological types, grading and anatomical location over different time periods.

- The study compared the observed brain tumour incidence rates with modelled predicted incidence rates assuming a causal association with mobile phone use.

- Mobile phone subscription data and information from surveys may not accurately represent mobile phone use patterns in adults.

head, the brain is exposed to much higher levels of radiofrequency $(\mathrm{RF})$ radiation than the rest of the body ${ }^{1}$ and there has been continuing concern of a possible association with brain cancer. Several case-control and registry-based cohort studies have found little evidence to support such an association. ${ }^{2}$ However a few other case-control studies, most notably the Interphone study (2010) and a Swedish study by Hardell et al have reported modest to large associations with glioma, the most common type of primary brain tumour. $^{3-5}$ These studies have generally found no association with other brain tumour types such as meningioma. Based on these results, the International Agency for Research on Cancer (IARC) has classified RF as 'possibly carcinogenic to humans'. ${ }^{6}$

From a public health perspective, given that the great majority of the population regularly uses mobile phones, even a relatively small excess risk would result in a significant number of additional brain tumour cases. In time, such an increase would be observable in cancer surveillance data sources. ${ }^{7}$ The World Health Organization (WHO) has previously identified as a high research priority the monitoring of brain tumour incidence trends through well-established population-based 
cancer registries and combined with population exposure data. $^{8}$

Since the WHO recommendation, a limited number of ecological studies have shown that although the prevalence of mobile phone use (usually measured through the number of mobile phone accounts) has seen a massive increase, the time trends of brain tumour incidence have remained fairly stable. ${ }^{910}$ Other studies have shown increases in certain brain tumour subtypes or specific anatomical locations. ${ }^{1011}$ However, it has been suggested that the introduction of better diagnostic methods (CT and MRI) have improved the detection of brain cancers which leads to increased population incidence. ${ }^{12}$ Further, a few recent studies, most notably in the USA and Australia, have shown that predicted incidence rates based on the associations reported by the Interphone and Hardell studies for 'heavy' mobile phone users are higher than the observed rates. ${ }^{1314}$ Apart from the study by Little et $a l,{ }^{13}$ previous results have generally failed to show the incidence trends for different brain tumour histological and topographical types. ${ }^{13}$ Further, the simulation of expected rates in these studies was only performed for a latency period of 10 years and if there is an association with mobile phone use the latency could be longer.

In this study, we analysed the incidence trends of brain tumour for three distinct time periods to ascertain the influence of improved diagnostic methods and increase in mobile phone use. The analysis considered different histological types and subtypes, glioma grades and glioma anatomical sites. We further compared the observed incidence during the period of substantial mobile phone use (2003-2013) with predicted incidence for the same period based on relative risks (RRs) reported by the two epidemiological studies forming the basis of the IARC classification. ${ }^{34}$

\section{METHODS}

\section{Collection of incidence data}

Incidence data on primary cancers of the brain and central nervous system diagnosed between 1982 and 2013 inclusive (the latest available) were obtained from the Australian Institute of Health and Welfare (AIHW). Reporting of incident invasive cancer is mandatory in all Australian states and territories and the AIHW has been collecting and reporting national data on brain cancer incidence since 1982. The data included information on primary anatomical site (International Classification of Diseases Version 10, ICD-10 topography codes, C70C72), histology, diagnosis year and diagnosis age (in 5 year groups: $0-4,5-9 \ldots 80-84,85+)$. Data were not available for one Australian state (New South Wales) for the year 2013.

\section{Patient and public involvement}

Patients or the public were not involved in this study.

\section{Statistical analysis of observed incidence}

Based on the results of the Interphone study, we analysed intracranial brain cancer incidence in adults aged 20-59;
Table 1 International Classification of Diseases Version 10 histology and topography codes

\begin{tabular}{ll}
\hline Histology & \\
\hline Glioma & $9380-9480$ \\
\hline Glioblastoma & $9440-9442$ \\
\hline Meningioma & $9530-9539$ \\
\hline Other & $8010-9371,9490-9508,9540-9561$ \\
\hline Unspecified & $8000-8004$ \\
\hline Glioma grade & \\
\hline Low (I and II) & $9384,9391,9393,9400,9410,9411,9420$, \\
& $9421,9424,9425,9450$ \\
\hline High (III and IV) & $9381,9392,9401,9440-9442,9451$, \\
\hline Unspecified & $9470-9474,9480$ \\
\hline Topography & $9380,9382,9390,9423,9430,9460$ \\
\hline Frontal & C711 \\
\hline Temporal & C712 \\
\hline Parietal & C713 \\
\hline Other locations & $\mathrm{C} 700$, C701, C709, C710, C714-C717 \\
\hline Overlapping & $\mathrm{C} 718$ \\
\hline Unspecified & $\mathrm{C} 719$ \\
\hline
\end{tabular}

neoplasms of the spinal cord, cranial nerves and other parts of central nervous system (ICD-10 code C72) were excluded. Annual age-standardised incidence rates per 100000 person-years were calculated separately for males, females and both genders by using WHO's standard population. Histology was analysed by categorising glioma, meningioma, other histological types and brain cancers with unspecified histology based on WHO's Classification of tumours of the central nervous system. ${ }^{15}$ We further analysed glioma by categorising glioblastoma (which is the most common brain tumour subtype), glioma grade (low, high and unspecified) and glioma location (frontal lobe, temporal lobe, parietal lobe, other locations, overlapping lobes and unspecified). The categories analysed and their respective ICD-10 codes are shown in table 1 .

A large number of tumours had unspecified classifications, particularly for glioma grade and glioma location. We approximated the classification of unspecified tumours by recalculating the adjusted rates for each year by adding the unspecified group to the other groups in proportion to the distribution of specified tumours.

The incidence rates were low compared with the population at risk so the variability in the observed cases was assumed to follow a Poisson distribution. ${ }^{16}$ Analyses of incidence time trends were carried out using Poisson regression to estimate the annual percentage change (APC) in the incidence, with corresponding $95 \%$ CI over three time periods: 1982-1992 (representing increased CT and MRI use), 1993-2002 (representing advances in MRI) and 2003-2013 (representing substantial and increasing mobile phone use; more than $65 \%$ of the population). ${ }^{17}$ Lowess smoothing was used in the graphical representation of the time trends. 


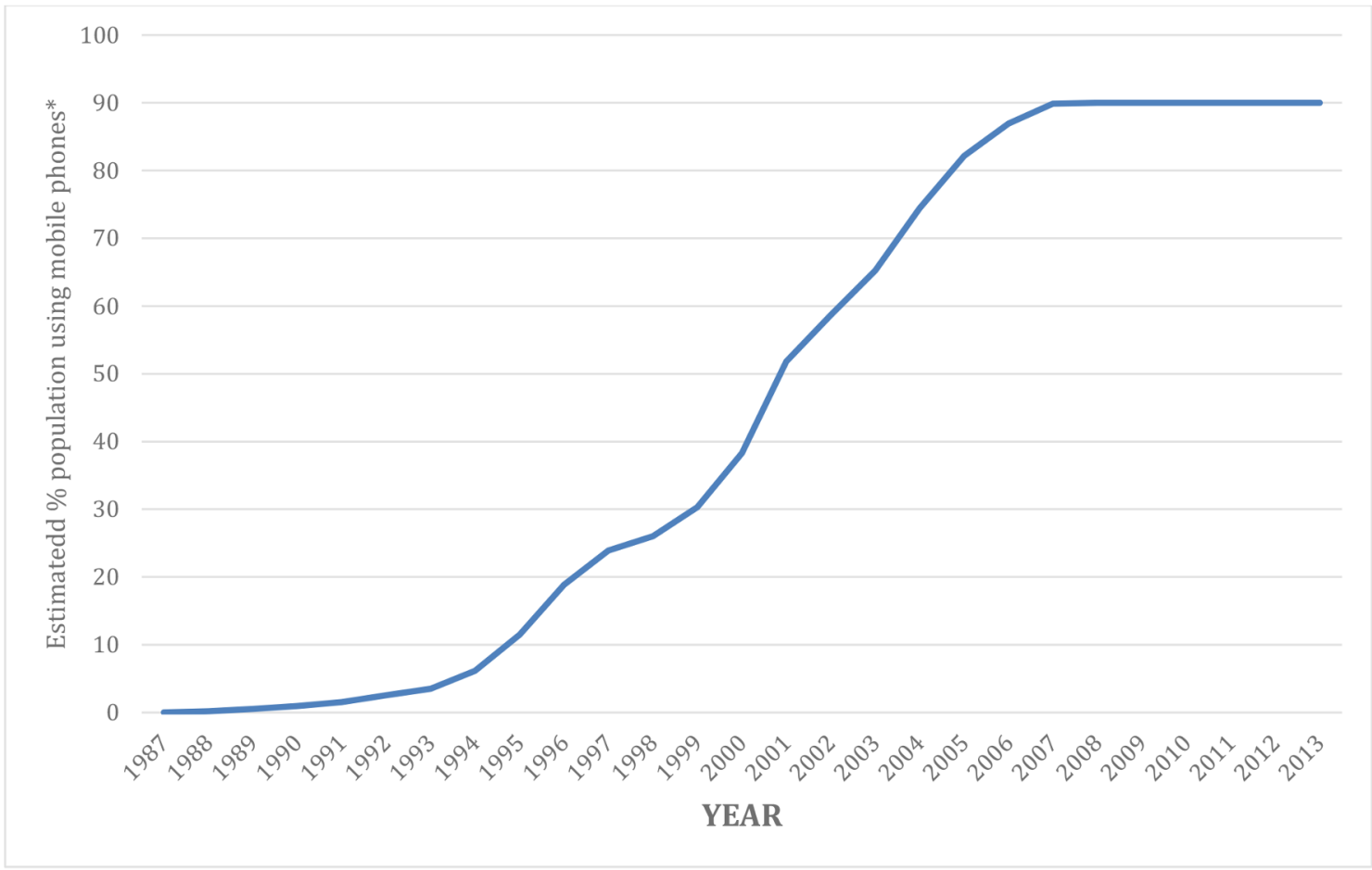

${ }^{\star}$ Based on subscription information from industry and consumer surveys

Figure 1 Estimated percentage of Australian population using mobile phones.

\section{Mobile phone use data sources}

Mobile phone use was estimated using information on mobile phone accounts and survey data on actual use. Data on the annual number of mobile phone accounts from 1987, when mobile telephony first commenced in Australia, to 2013 were obtained from the national telecommunications regulator, the Australian Communications and Media Authority (ACMA). The number of mobile phone accounts per capita for each year was calculated by dividing the number of accounts by the total Australian population in that year (obtained from the Australian Bureau of Statistics), noting that since 2008 the annual number of accounts has been exceeding the number of people in the population. These data are not a true indication of mobile phone use as some users may have had more than one account and other users no account. A consumer survey conducted by ACMA reported that approximately $90 \%$ of the population used mobile phones in the years $2009-2013 .{ }^{18}$ We estimated the annual prevalence of mobile phone use (shown in figure 1) by multiplying the annual number of accounts per capita by a factor of $0.9 .{ }^{18}$ It was not possible to stratify prevalence of use by age or gender; thus, an overall estimate of prevalence is provided equally for all ages across the 20-59 age range and for both males and females.

\section{Statistical analysis of predicted incidence}

With the assumption that mobile phone use is associated with glioma in adults as reported by the Interphone and Swedish studies, we calculated predicted incidence rates and time trends by applying various RRs (1.5, 2, 2.5,
3) and latency periods (1, 5, 10, 15, 20 years) for three different mobile phone use scenarios:

a. All users-RRs were applied to all mobile phone users.

b. (Heavy users-RRs were applied to heavy mobile phone users (defined as 19\% of mobile phone users by the Interphone study).

c. Regular users and heavy users-RR of 1.5 applied to regular users ( $81 \%$ of all users) and RRs of 2, 2.5 and 3 applied to heavy users (19\% of all users).

The annual predicted incidence rates were calculated for the period 1987-2013 using the formula:

Predicted incidence $=\left(\mathrm{P} \times \mathrm{RR} \times \mathrm{I}_{\mathrm{B}}\right)+\left((1-\mathrm{P}) \times \mathrm{I}_{\mathrm{B}}\right)$

where $\mathrm{P}$ denotes the annual prevalence of mobile phone use, RR and $\mathrm{I}_{\mathrm{B}}$ the premobile phone baseline incidence from 1982 to 1987 . CIs and statistical significance of observed and expected incidence rates were calculated using Poisson CIs as described in Ulm. ${ }^{19}$ Analyses of predicted incidence time trends were carried out by estimating the APC for the period 2003-2013, representing the time that mobile phone use increased rapidly.

We used Stata/SE V.15.0 for all analyses. The reporting of our study conforms to the Strengthening the Reporting of Observational Studies in Epidemiology statement. ${ }^{20}$

\section{RESULTS}

\section{Observed incidence}

There was a total of 16825 eligible brain cancer cases aged 20-59 (10 083 males and 6742 females) that were diagnosed between 1982 and 2013. Of these 15758 $(93.7 \%)$ were gliomas, $312(1.9 \%)$ were meningiomas, 
$239(1.4 \%)$ were other histological types and $516(3.1 \%)$ were tumours of unspecified histology. The most common brain tumour subtype was glioblastoma $(7326,43.5 \%)$. Of the gliomas, $4699(29.8 \%)$ were low grade, $9300(59 \%)$ were high grade and $1759(11.2 \%)$ were of unspecified grade. The most common glioma anatomical location was the frontal lobe (4422, $28.1 \%$ ), followed by the temporal lobe $(2952,18.7 \%)$ and parietal lobe $(2272,14.4 \%)$. There were $2372(15.1 \%)$ tumours in other locations, $968(6.1 \%)$ overlapping locations and $2772(17.6 \%)$ with unspecified location.

The observed incidence rates between 1982 and 2013 are shown in figure 2 for both genders and online supplementary figure A for males and females separately. Further, the observed incidence trends (given as APC) over the time periods 1982-1992, 1993-2002 and 2003-2013 are shown in table 2 for both genders and online supplementary table A for males and females separately. The overall brain tumour rates remained stable in all three time periods and the trends were similar for males and females. Glioblastoma increased during the period that saw advances in MRI (1993-2002) while it remained stable during the period of substantial mobile phone use (20032013); this later period also saw a decrease in other glioma subtypes. The APC for glioblastoma in both genders for the entire observation period, that is, 1982-2013 (not shown in table 2) was 1.45 (1.11-1.79). There was a strong decreasing trend in brain tumours with unspecified histology during the period of increased CT and MRI use (1982-1992). With the redistribution of unspecified tumours, there were no significant changes to these histological trends (table 3 for both genders and online supplementary table B for males and females separately).

Looking at glioma grade in table 2, high-grade gliomas increased during both periods of improved diagnosis while low-grade gliomas decreased during the periods of advances in MRI (1993-2002) and substantial mobile phone use (2003-2013). There was a strong decreasing trend in gliomas with unspecified grade during the period of increased CT and MRI use (1982-1992). The redistribution of unspecified tumours did not change the glioma grade trends (table 3 ).

For glioma location in table 2, there were increasing trends for all locations and a strong decreasing trend for unspecified location during the period of increased CT and MRI use (1982-1992). There were also increases in the frontal and temporal lobes and a smaller decrease in unspecified location during the period of advances in MRI (1993-2002); this period also had a very large decrease in gliomas with overlapping location. During the period of substantial mobile use, there were no increases in any of the locations apart from the frontal lobe and there was a strong decrease in unspecified location. With the redistribution of a high number of gliomas with unspecified and overlapping location, there was a much lower increasing trend only for gliomas in the frontal lobe during all three periods and a large increase in the parietal lobe during the first period (table 3 ).

\section{Predicted incidence}

Assuming a causal association between mobile phone use and glioma, the predicted incidence trends for both genders during 2003-2013 by applying various RRs, latency periods and mobile phone use scenarios are shown in table 4 . The predicted incidence trends showed an increase for most mobile phone use scenarios and latency periods that were modelled apart from a 20-year latency period. There were also no statistically significant increases when applying the model to only heavy users for RRs less than 3. The highest expected trends were generally seen for a 10-year latency period, which was the latency period associated with mobile phones and brain tumour as reported in the Interphone and Swedish studies.

The observed and predicted glioma incidence rates for both genders from 1987 to 2013 are shown in figure 3 for a 10-year latency and online supplementary figure B for 1, 5,15 and 20 years latencies. With an RR of 2 for all mobile phone users and a latency of 10 years, the predicted incidence rate for both genders in 2013 was 7.3 per 100000 people (95\% CI 6.7 to 7.9 ) compared with the observed 4.5 per 100000 . The predicted rates increase to $8.7(95 \%$ CI 8.1 to 9.3 ) and 10.2 (95\% CI 9.5 to 10.8 ) per 100000 for RRs of 2.5 and 3, respectively. With an RR of 1.5 for regular users and an RR of 2 for heavy users and a latency of 10 years the predicted rate was 6.1 per $100000(95 \%$ CI 5.6 to 6.6$)$; increasing to 6.4 (95\% CI 5.9 to 6.9 ) and 6.7 (95\% CI 6.1 to 7.2 ) when applying RRs of 2.5 and 3 to heavy users, respectively. Assuming a latency of 15 years, the predicted incidence rates in 2013 were also higher compared with the observed rate. The model did not show an increasing trend for a latency of 20 years.

\section{DISCUSSION}

The results of our study showed that the overall brain tumour rates in adults aged 20-59 years showed no increasing or decreasing trend. This is in line with studies showing stable brain tumour trends in other countries. ${ }^{10-12}$ Furthermore, the trends in our study were stable for different histological types, like glioma, which has been reported in some case-control studies as being associated with mobile phone use. ${ }^{34}$ The all glioma incidence rates were stable in both the periods before (1982-1992, 1993-2002) and the period after (2003-2013) substantial mobile phone use. For a causal relationship between mobile phone use and brain cancer, one would expect an increasing trend in the later period and no trend in the earlier periods.

There has been limited research showing the time trends of histological subtypes and particularly glioblastoma, which is the most common and most malignant brain tumour subtype in adults. ${ }^{5}$ Philips $e t a l^{21}$ reported that the incidence of glioblastoma more than doubled in England between 1995 and 2015; however, the authors did not analyse different periods to investigate the impact of mobile phone use. ${ }^{21}$ Dobes $e t a t^{22}$ 
Histology

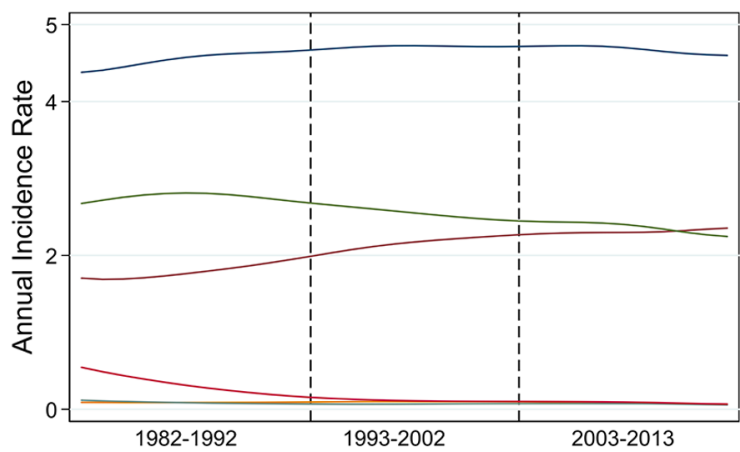

Year

- Frontal $\quad$ Temporal $\quad$ Parietal $\quad$ Other locations $\quad$ Overlapping $\quad$ Unspecified

\section{Glioma Grade}

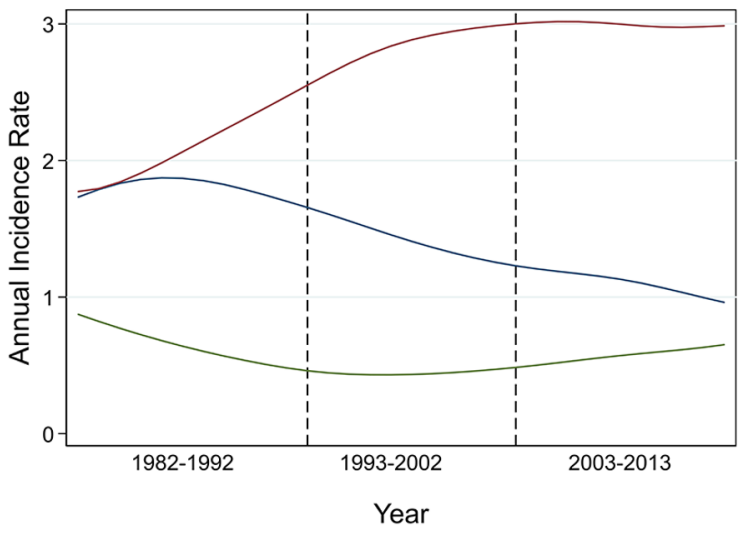

- Low - High - Unspecified

Topography

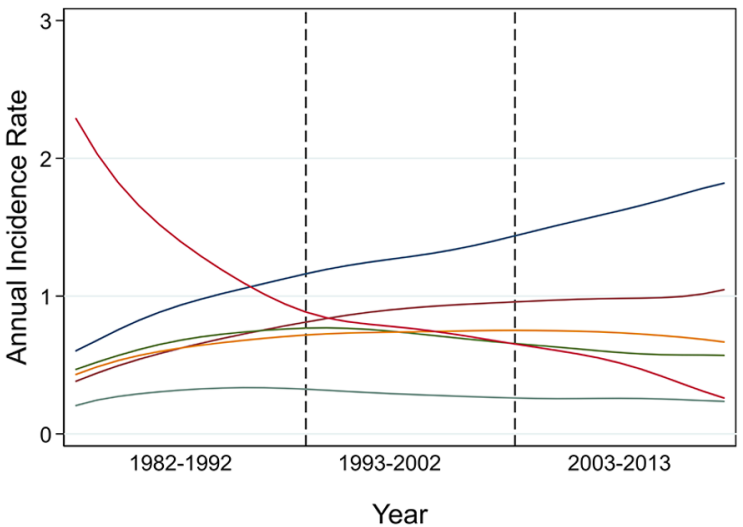

- Frontal - Temporal $\quad$ Parietal $\quad$ Other locations $\quad$ Overlapping Unspecified

*Lowess smoothing

Figure 2 Observed incidence rates (smoothed*) in adults (both genders, 20-59 years old) during 1982-2013. 
Table 2 Observed age-standardised brain tumour incidence trends in adults (both genders, 20-59 years old) during increased CT and MRI use (1982-1992), advances in MRI use (1993-2002) and substantial mobile phone use (2003-2013)

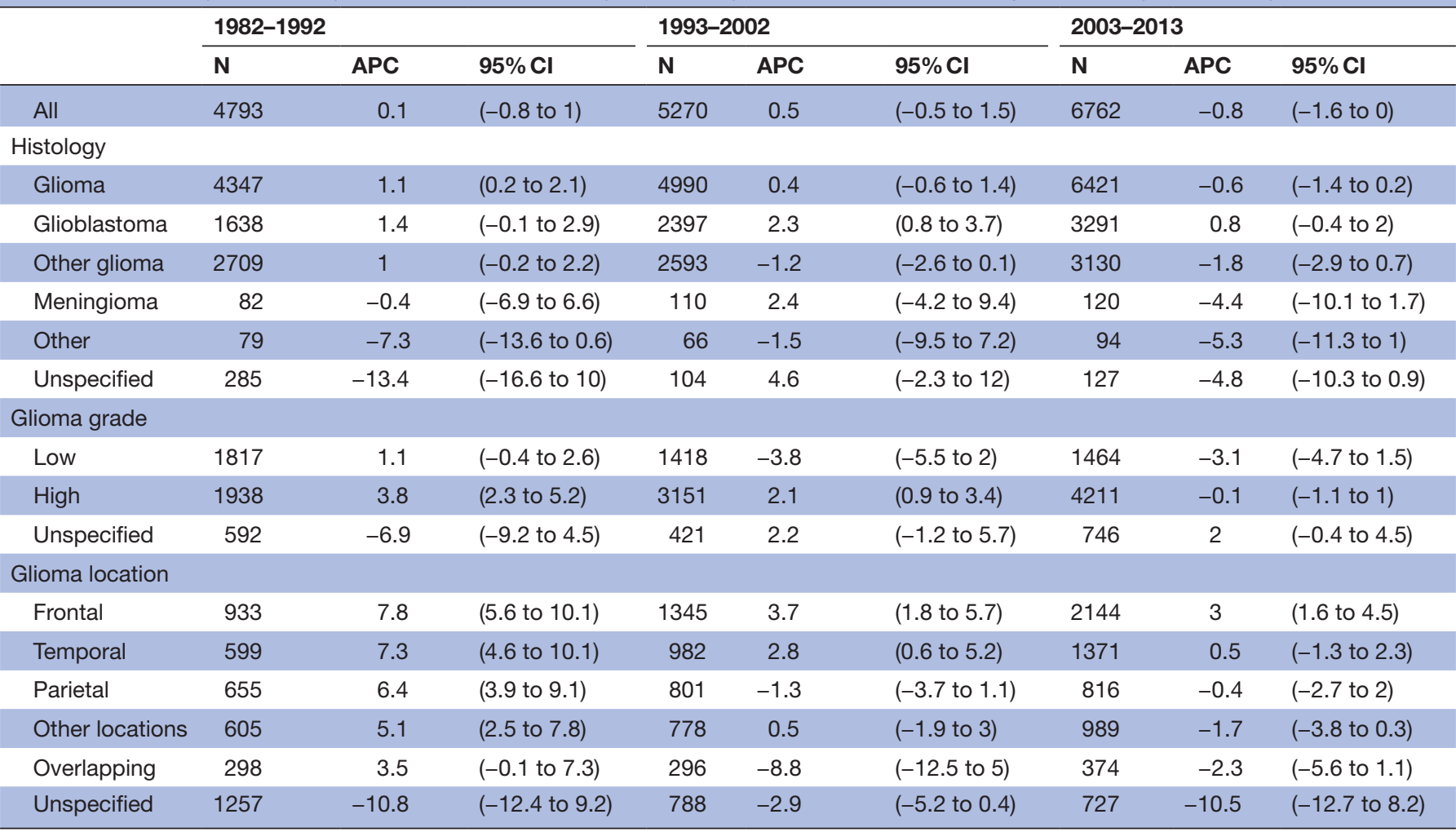

APC, annual percentage change.

reported an increasing trend in glioblastoma incidence in Australia between 2000 and 2008 in people aged 65 years or older; noting that the cases were ascertained directly from neurological centres. ${ }^{22}$ Our study used all the national incident brain cancer registrations available through Australia's high-quality state and territory

Table 3 Observed age-standardised brain tumour incidence trends in adults (both genders, 20-59 years old) after redistribution of unclassified tumours

\begin{tabular}{|c|c|c|c|c|c|c|c|c|c|}
\hline & \multicolumn{3}{|c|}{ 1982-1992 } & \multicolumn{3}{|c|}{ 1993-2002 } & \multicolumn{3}{|c|}{ 2003-2013 } \\
\hline & $\mathbf{N}$ & APC & $95 \% \mathrm{Cl}$ & $\mathbf{N}$ & APC & $95 \% \mathrm{Cl}$ & $\mathbf{N}$ & APC & $95 \% \mathrm{Cl}$ \\
\hline All & 4793 & 0.1 & $(-0.8$ to 1$)$ & 5270 & 0.5 & $(-0.5$ to 1.5$)$ & 6762 & -0.8 & $(-1.6$ to 0$)$ \\
\hline \multicolumn{10}{|l|}{ Histology } \\
\hline Glioma & 4623 & 0.2 & $(-0.7$ to 1.2$)$ & 5094 & 0.5 & $(-0.5$ to 1.5$)$ & 6547 & -0.7 & $(-1.5$ to 0.1$)$ \\
\hline Glioblastoma & 1746 & 0.4 & $(-1.1$ to 1.9$)$ & 2445 & 2.4 & (0.9 to 3.8$)$ & 3353 & 0.7 & $(-0.5$ to 1.9$)$ \\
\hline Other glioma & 2886 & 0.1 & $(-1$ to 1.2$)$ & 2649 & -1.1 & $(-2.5$ to 0.2$)$ & 3195 & -1.9 & $(-3$ to 0.8$)$ \\
\hline Meningioma & 84 & -1.6 & $(-7.9$ to 5.2$)$ & 110 & 2.4 & $(-4.2$ to 9.4$)$ & 120 & -4.4 & $(-10.1$ to 1.7$)$ \\
\hline Other & 82 & -8.6 & $(-14.7$ to 2$)$ & 66 & -1.5 & $(-9.5$ to 7.2$)$ & 94 & -5.3 & $(-11.3$ to 1$)$ \\
\hline \multicolumn{10}{|l|}{ Glioma grade } \\
\hline Low & 2107 & -0.2 & $(-1.5$ to 1.2$)$ & 1548 & -3.6 & $(-5.3$ to 1.9$)$ & 1659 & -2.8 & $(-4.3$ to 1.3$)$ \\
\hline High & 2240 & 2.4 & (1.1 to 3.7$)$ & 3442 & 2.3 & (1.1 to 3.5$)$ & 4762 & 0.2 & $(-0.7$ to 1.2$)$ \\
\hline \multicolumn{10}{|c|}{ Glioma topography } \\
\hline Frontal & 1447 & 1.8 & (0.2 to 3.5$)$ & 1719 & 2.3 & (0.6 to 4$)$ & 2580 & 1.6 & (0.3 to 2.9$)$ \\
\hline Temporal & 929 & 1.8 & $(-0.2$ to 3.9$)$ & 1252 & 1.5 & $(-0.5$ to 3.5$)$ & 1656 & -1.2 & $(-2.8$ to 0.4$)$ \\
\hline Parietal & 803 & 3.4 & (1.2 to 5.7$)$ & 894 & -2 & $(-4.2$ to 0.3$)$ & 880 & -1.1 & $(-3.3$ to 1.1$)$ \\
\hline Other locations & 948 & -0.5 & $(-2.5$ to 1.5$)$ & 996 & -0.8 & (-3 to 1.4$)$ & 1198 & -3.3 & $(-5.1$ to 1.4$)$ \\
\hline
\end{tabular}

APC, annual percentage change. 


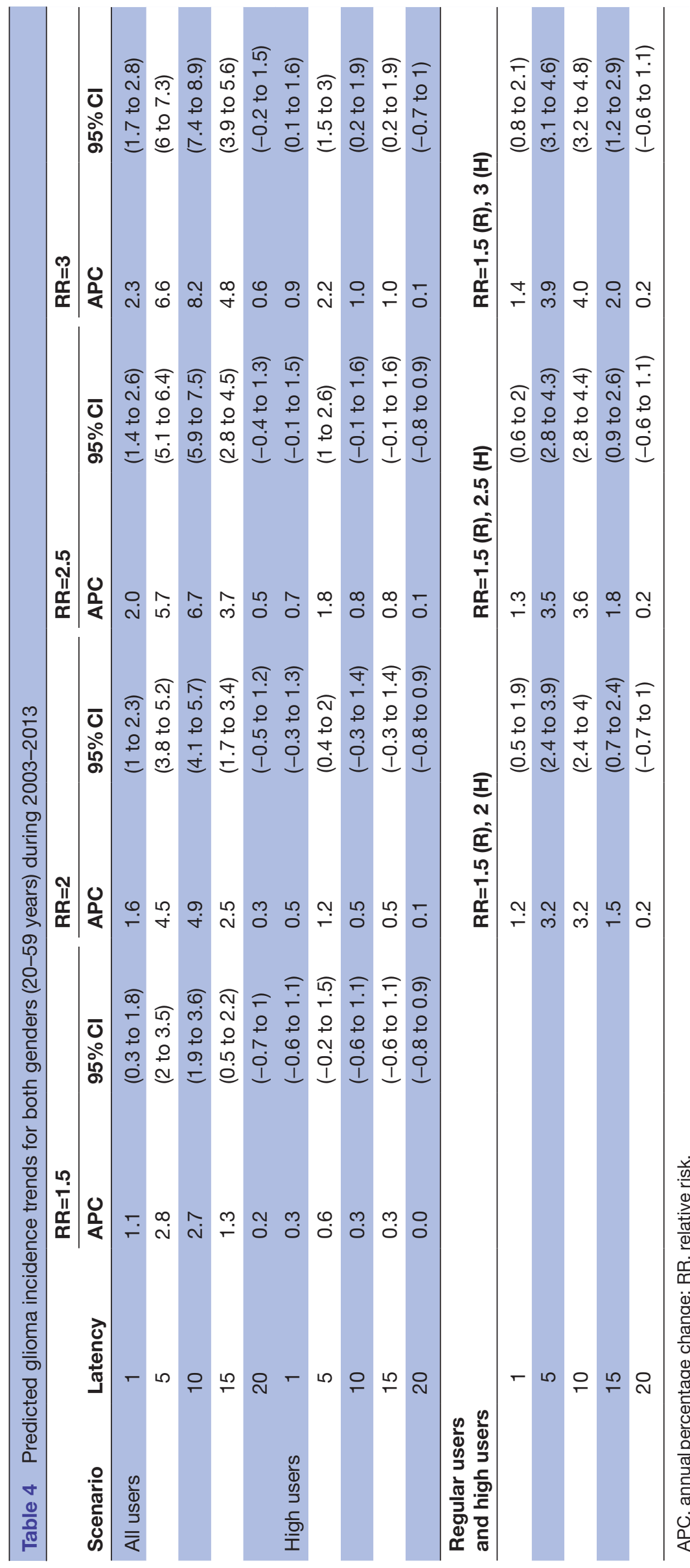



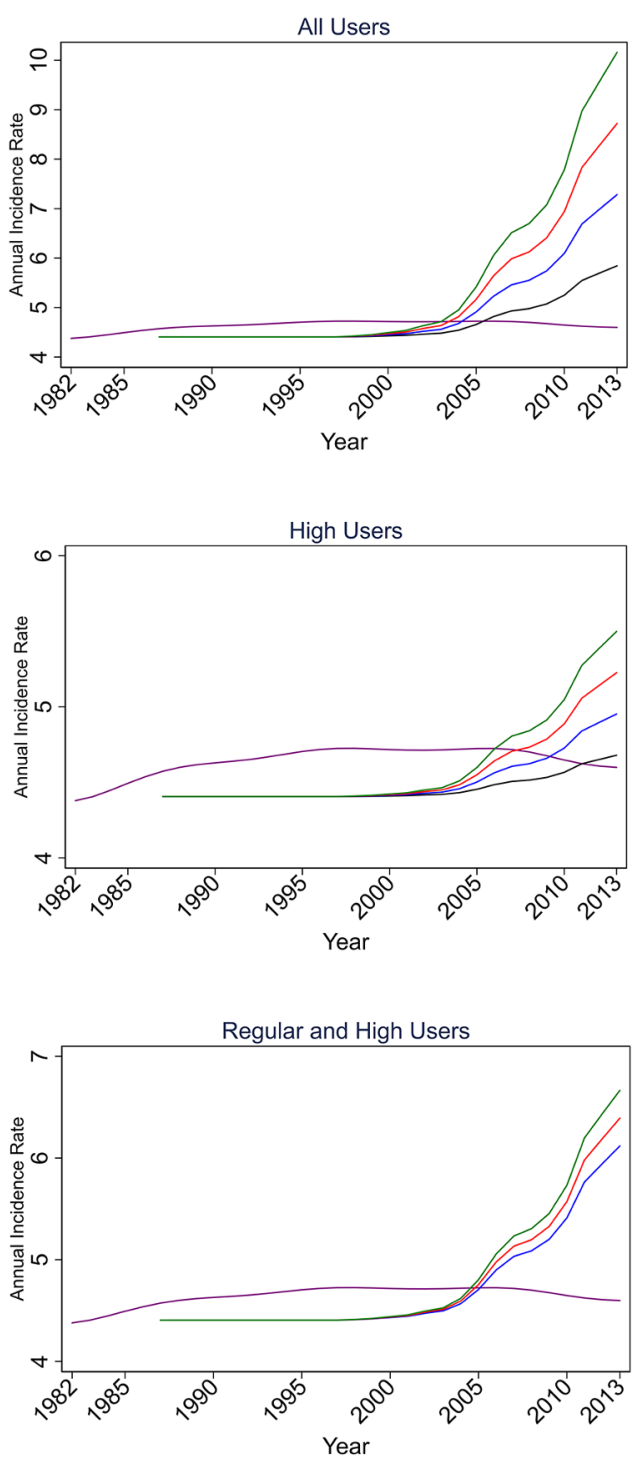

\section{- observed(lowess) $\quad-\mathrm{RR}=1.5 \quad-\mathrm{RR}=2 \quad-\mathrm{RR}=2.5 \quad-\mathrm{RR}=3$}

*Lowess smoothing

Figure 3 Observed (smoothed*) and predicted (10-year latency) incidence rates in adults (both genders, 20-59 years old) during 1982-2013. RR, relative risk.

population-based cancer registration system. Registration is mandatory and histological verification rates exceed $85 \% .{ }^{14}$ In our study, which focused on the age group most likely to be affected by mobile phone use, there was an increasing trend for glioblastoma when looking at the entire observation period (1982-20130). However, when looking at different time periods, there was no increase in the glioblastoma rates during the period of substantial mobile phone use but there was an increase in the glioblastoma rates in the earlier periods: 19821992 (non-statistically significant increase), which saw increased use of CT and MRI, and 1993-2002 (statistically significant increase) which saw further advances in MRI.
Technological developments in MRI during 1993-2002, including diffusion and perfusion imaging, improved significantly the discrimination of brain tumour types and subtypes. ${ }^{1723}$ Other factors, such as improved access to care and an increase in the number of specialists, may also have played a role in the increase. ${ }^{9}$ Earlier studies investigating trends in brain tumour subtypes including glioblastoma have commented that increases in certain subtypes are accompanied by decreases in other subtypes while overall brain tumour incidence has remained stable. ${ }^{2425}$ These studies suggest improvements in diagnostic technology as the reason for increasing trends in certain brain tumour subtypes. ${ }^{24} 25$ 
The results on histology are consistent with the results by grade, as high-grade glioma is approximately equivalent to glioblastoma. During the period of advances in MRI, there was an increase for high-grade lesions and a decrease for low-grade, both which levelled off during the period of substantial mobile phone use. These results are consistent with incidence trends reported by Barchana $e t a l^{26}$ for low-grade and high-grade gliomas in Israel between 1980 and 2009. ${ }^{26}$ Furthermore, there was a strong decrease for unspecified histology and for unspecified grade during the first period, and this is likely due to improvements in diagnosis using CT and histopathological classification. ${ }^{27}$ There have also been shifts in classifying subtypes and grade in updated editions of WHO classification; for example, WHO 2000 classification induced a shift from anaplastic astrocytoma to glioblastoma.

The results on anatomical location showed that there was an increase in gliomas located in the temporal and parietal lobes prior to the period of substantial mobile phone use, but not during it. There were increases for gliomas located in the frontal lobe both before and during increased mobile phone use, however, the temporal and parietal lobes are more highly exposed to RF radiation than other brain sites when using mobile phones. Cardis et $a l^{1}$ reported that depending on the type of mobile phone and the manner in which it is used, the RF energy absorption is at least several times higher in the temporal lobe than in the frontal lobe. ${ }^{1}$ In our data there was a large number of gliomas with unspecified or overlapping location. Reclassification of these did reduce the trends for the temporal lobe during the periods before substantial mobile phone use, and for the frontal lobe during all the periods.

In our study, we also compared the observed incidence with a modelled predicted incidence assuming a causal association between mobile phone use and glioma as reported in the Interphone and Hardell studies. The results suggest that, if the effects of mobile phones on glioma risk are real, then the incidence rates would be far higher than those observed. We modelled predicted incidence rates for a variety of latency periods up to 20 years whereas previous studies only included latencies up to 10 years. ${ }^{12}{ }^{13}$ Previous studies by Little $e t a l^{3}$ and more recently by Chapman et $a l^{14}$ have also shown that when modelling the RRs from the Interphone and Hardell studies and assuming a latency of 10 years, the predicted incidence rates are much higher. ${ }^{13} 14$ The exact causes of brain cancer are unknown and so is the latency period for the disease. Ionising radiation has been shown to induce brain cancer by causing DNA damage with a latency period of about 5 or more years. ${ }^{28} \mathrm{RF}$ exposure is non-ionising radiation which does not cause direct DNA damage and it has been argued that a possible effect would have a latency shorter than 5 years. ${ }^{13}$ However, it has also been argued that the latency for an increased risk of brain cancer could be both short and long, indicating tumour initiation and promotion, respectively. ${ }^{29}$ In our study, we modelled predicted incidence rates for a variety of latency periods up to 20 years. Our model found that the predicted incidence rates were higher than the observed rates for a latency period up to 15 years. A longer observation period is required in order to model longer latency periods.

The present study has some limitations. The accuracy of the Australian cancer registration system in the early periods when it began in the $80 \mathrm{~s}$ is unknown for all the states and territories. In Northern Territory mandatory notification of cancer cases by pathology laboratories was introduced in 1991. Case ascertainment was found to be approximately 40\% incomplete for the period 1981-1986 and approximately $10 \%$ incomplete for the period 19871990. However, the Northern Territory makes up a very small proportion of Australia's population $(\sim 1 \%) .{ }^{30}$ All Australian state and territory registries conform to the IARC's criteria for population-based cancer registration, are 'A' rated and have their data published in the 'Cancer Incidence in Five Continents' series. ${ }^{1431}$

We estimated mobile phone use using information on mobile phone accounts, and this may not be a true indicator of actual use as some people may have multiple accounts and others may use a phone without having an account. We mitigated this by also using data from a consumer survey conducted by the national telecommunications regulator on the proportion of the population using mobile phones. Information from the survey was only available from the years 2009 to 2013 and this was applied to data on the annual number of mobile phone accounts from 1987. However, mobile phone use patterns have likely changed from 1987 to 2009. Further, the exposure metric is unclear when investigating whether mobile phone use is implicated in brain cancer risk. Prevalence of phone use is a de facto measure for the amount of RF energy a person is receiving when using a mobile phone, and changes in technology and patterns of individual use were not taken into account in this investigation. For example, advances in mobile telephony have resulted in greatly reduced output power of the phones and the evolving use of mobile phones has resulted in less actual calling time with the phone against the head.

We estimated the prevalence of mobile phone use equally across the 20-59 age range and both males and females. The use of subscription data in early years is likely to underestimate prevalence of use in males and overestimate it in females given that users in early years were middle-aged working men on company mobile phone subscriptions. ${ }^{14}$ In later years mobile phone use became equal between the two genders. ${ }^{32}$

For information on the proportion of regular and heavy mobile phone users, we used data from the Interphone study, which also included data from Australia. Mobile phone use in the Interphone study was self-reported, relying on participants' recall of past phone use. ${ }^{3}$ Sensitivity analyses on the Interphone methodology reported that for short term recall (up to a year) there was underestimation of phone use by regular users and overestimation by heavy users. ${ }^{33}$ For longer recall (3-5 years), there 
was an underestimation of number of calls and an overestimation on the duration of calls for all users. ${ }^{34}$ Based on these findings, it is likely that the proportion of heavy users in our study is overestimated. Further, the real patterns of mobile phone use may be more complex than the scenarios we modelled.

Finally this is an ecological observational study, not based on individual data, thus, it is not possible to account for confounding factors. This study design is appropriate to define global trends. The results of our study are prone to the ecological fallacy and small risks in subgroups in the population may not have been detected. Further, the stable trend in brain tumour incidence could have concealed a true increasing risk related to mobile phone use which appeared flat due to declines in other risk factors.

In conclusion, we found no evidence that mobile phone use increased any brain tumour histological types or subtypes. There was an increase in the incidence of glioblastoma prior to the rapid increase in mobile phone use which was most likely due to improved diagnosis from MRI. Furthermore, there was no increase in gliomas of the temporal lobe, which is the most exposed location, during the period of substantial mobile phone use. The increase in gliomas of the temporal lobe and decrease in gliomas of unspecified location during the periods prior to substantial mobile phone use are in line with the theory of improved diagnosis from CT and MRI. Further, the predicted rates were higher than the observed rates for latency periods up to 15 years. These results do not support an association between mobile phone use and brain tumour, although the possibility of a small risk or a latency period of more than 15 years cannot be excluded. Future research should continue to investigate trends in brain tumour histological types, grading and anatomical location for a possible increase with a longer latency period.

Acknowledgements We would like to thank Jeffrey Rosenfeld who consulted on the diagnosis of brain tumours, Rick Tinker who assisted in the initial planning of the study, Blake Orr who assisted with the statistical analysis and Rohan Mate edited the draft paper.

Contributors KK, ME, GB and RJC designed the study. KK and LT collected the data. KK and ME reviewed the literature. KK, ME, GB and RJC directed the analyses which were carried out by KK, MS and LT. KK wrote the initial draft. All authors critically revised the manuscript for intellectual content and approved the final version.

Funding This work was supported by National Health and Medical Research Council grant APP1042464.

Disclaimer The funder had no role in the study design, data collection or analysis, decision to publish or preparation of the manuscript.

Competing interests ME has received personal fees from the New Zealand Government Health Department on an independent report on specified health issues of electric and magnetic fields.

Patient consent Not required.

Ethics approval The SA Department for Health and Ageing Human Research Ethics Committee granted ethics approval for use of the SA data (Reference Number: HREC/17/SAH/41)

Provenance and peer review Not commissioned; externally peer reviewed.
Data sharing statement No additional data are available.

Open access This is an open access article distributed in accordance with the Creative Commons Attribution Non Commercial (CC BY-NC 4.0) license, which permits others to distribute, remix, adapt, build upon this work non-commercially, and license their derivative works on different terms, provided the original work is properly cited, appropriate credit is given, any changes made indicated, and the use is non-commercial. See: http://creativecommons.org/licenses/by-nc/4.0/.

\section{REFERENCES}

1. Cardis E, Deltour I, Mann S, et al. Distribution of RF energy emitted by mobile phones in anatomical structures of the brain. Phys Med Biol 2008;53:2771-83.

2. Scientific Committee on Emerging and Newly Identified Health Risks. Final opinion on potential health effects ofexposure to electromagnetic fields (EMF). 2015.

3. INTERPHONE Study Group. Brain tumour risk in relation to mobile telephone use: results of the INTERPHONE international case-control study. Int J Epidemiol 2010;39:675-94.

4. Hardell L, Carlberg M, Hansson Mild K. Pooled analysis of casecontrol studies on malignant brain tumours and the use of mobile and cordless phones including living and deceased subjects. Int $J$ Oncol 2011;38:1465-74.

5. Ostrom QT, Bauchet L, Davis FG, et al. The epidemiology of glioma in adults: a "state of the science" review. Neuro Oncol 2014;16:896-913.

6. Baan R, Grosse Y, Lauby-Secretan B, et al. Carcinogenicity of radiofrequency electromagnetic fields. Lancet Oncol 2011;12:624-6.

7. Röösli M, Michel G, Kuehni CE, et al. Cellular telephone use and time trends in brain tumour mortality in Switzerland from 1969 to 2002. Eur J Cancer Prev 2007;16:77-82.

8. World Health Organization. WHO research agenda for radiofrequency fields. 2010.

9. Inskip PD, Hoover RN, Devesa SS. Brain cancer incidence trends in relation to cellular telephone use in the United States. Neuro Oncol 2010;12:1147-51.

10. Deltour I, Auvinen A, Feychting M, et al. Mobile phone use and incidence of glioma in the Nordic countries 1979-2008: consistency check. Epidemiology 2012;23:301-7.

11. de Vocht F, Burstyn I, Cherrie JW. Time trends (1998-2007) in brain cancer incidence rates in relation to mobile phone use in England. Bioelectromagnetics 2011;32:334-9.

12. Kim SJ, loannides SJ, Elwood JM. Trends in incidence of primary brain cancer in New Zealand, 1995 to 2010. Aust N Z J Public Health 2015;39:148-52.

13. Little MP, Rajaraman $P$, Curtis RE, et al. Mobile phone use and glioma risk: comparison of epidemiological study results with incidence trends in the United States. BMJ 2012;344:e1147.

14. Chapman S, Azizi L, Luo Q, et al. Has the incidence of brain cancer risen in Australia since the introduction of mobile phones 29 years ago? Cancer Epidemiol 2016;42:199-205.

15. Louis DN, Perry A, Reifenberger G, et al. The 2016 World Health Organization classification of tumors of the central nervous system: a summary. Acta Neuropathol 2016;131:803-20.

16. Jensen P. Cancer registration: principles and methods: IARC, 1991

17. Castillo M. History and evolution of brain tumor imaging: insights through radiology. Radiology 2014;273:S111-25.

18. Australian Communications and Media Authority. Communications report 2015-16. 2016

19. Ulm K. A simple method to calculate the confidence interval of a standardized mortality ratio (SMR). Am J Epidemiol 1990;131:373-5.

20. Von Elm E, Altman DG, Egger M, et al. The Strengthening the Reporting of Observational Studies in Epidemiology (STROBE) statement: guidelines for reporting observational studies. PLoS Med 2007;4:e296.

21 Philips A, Henshaw DL, Lamburn G, et al. Brain tumours: rise in Glioblastoma Multiforme incidence in England 1995-2015 suggests an adverse environmental or lifestyle factor. $J$ of Environment and Public Health. Forthcoming 2018.

22. Dobes M, Khurana VG, Shadbolt B, et al. Increasing incidence of glioblastoma multiforme and meningioma, and decreasing incidence of Schwannoma (2000-2008): Findings of a multicenter Australian study. Surg Neurol Int 2011;2.

23. Sanghvi DA. Recent advances in imaging of brain tumors. Indian $J$ Cancer 2009;46:82.

24. Jukich PJ, McCarthy BJ, Surawicz TS, et al. Trends in incidence of primary brain tumors in the United States, 1985-1994. Neuro Oncol 2001;3:141-51. 
25. Dubrow R, Darefsky AS. Demographic variation in incidence of adult glioma by subtype, United States, 1992-2007. BMC Cancer 2011;11:325.

26. Barchana M, Margaliot M, Liphshitz I. Changes in brain glioma incidence and laterality correlates with use of mobile phones--a nationwide population based study in Israel. Asian Pac J Cancer Prev 2012:13:5857-63.

27. Ho VK, Reijneveld JC, Enting RH, et al. Changing incidence and improved survival of gliomas. Eur J Cancer 2014;50:2309-18.

28. United Nations Scientific Committee on the Effects of Atomic Radiation. Effects of ionizing radiation: UNSCEAR 2006 report to the general assembly, with scientific annexes: United Nations Publications, 2009

29. Morgan LL, Miller AB, Sasco A, et al. Mobile phone radiation causes brain tumors and should be classified as a probable human carcinogen (2A) (review). Int J Oncol 2015;46:1865-71.
30. Condon J, Zhao Y, Armstrong B, et al. Northern territory cancer register data quality, 1981-2001: nt cancer registry, the cooperative research centre for aboriginal health, charles darwin university and the menzies school of health research. 2004.

31. Forman D, Bray F, Brewster D, et al. Cancer incidence in five continents, Vol. X (electronic version. Lyon: IARC, 2013.

32. Barr ML, Van Ritten JJ, Steel DG, et al. Inclusion of mobile phone numbers into an ongoing population health survey in New South Wales, Australia: design, methods, call outcomes, costs and sample representativeness. BMC Med Res Methodol 2012;12:177.

33. Vrijheid M, Cardis E, Armstrong BK, et al. Validation of short term recall of mobile phone use for the Interphone study. Occup Environ Med 2006;63:237-43.

34. Vrijheid M, Armstrong BK, Bédard D, et al. Recall bias in the assessment of exposure to mobile phones. J Expo Sci Environ Epidemiol 2009;19:369-81. 
Correction: Mobile phone use and incidence of brain tumour

histological types, grading or anatomical location: a population-based ecological study

Karipidis K, Elwood M, Benke G, et al. Mobile phone use and incidence of brain tumour histological types, grading or anatomical location: a population-based ecological study. BMJ Open 2018;8:e024489. doi: 10.1136/bmjopen-2018-024489.

The previous version of this manuscript contains some error in figure 2 legends. Since the paper was first published online the legend in the first graph of figure 2 has been edited. It should appear as follows:

Giloma, Glioblastoma, Other_glioma, Meningioma, Other, Unspecified.

Instead of

Frontal, Temporal, Parietal, Other locations, Overlapping, Unspecified.

Open access This is an open access article distributed in accordance with the Creative Commons Attribution Non Commercial (CC BY-NC 4.0) license, which permits others to distribute, remix, adapt, build upon this work non-commercially, and license their derivative works on different terms, provided the original work is properly cited, appropriate credit is given, any changes made indicated, and the use is non-commercial. See: http://creativecommons.org/licenses/by-nc/4.0/.

(c) Author(s) (or their employer(s)) 2018. Re-use permitted under CC BY-NC. No commercial re-use. See rights and permissions. Published by BMJ.

BMJ Open 2018;9:e024489corr1. doi:10.1136/bmjopen-2018-024489corr1

A) Check for updates 